\title{
A longitudinal and contextual analysis of media representation of business ethics
}

\author{
Barkemeyer, R., Holt, D., Figge, F. and Napolitano, G.
}

\author{
Please cite as: \\ Barkemeyer, R., Holt, D., Figge, F. and Napolitano, G. (2010), Longitudinal and contextual analysis of \\ media representation of business ethics, European Business Review, 22(4), pp. 377-396.
}

\begin{abstract}
$\star * * * * * * * * * * * * * * * * * *$
Abstract

Purpose: This paper presents an analysis of media representations of business ethics within 62 international newspapers to explore the longitudinal and contextual evolution of business ethics and associated terminology. Levels of coverage and contextual analysis of the content of the articles are used as surrogate measures of the penetration of business ethics concepts into society.

Design/Methodology/Approach: A text mining application based on two samples of data: analysis of 62 international newspapers from 1990-2008; analysis of the content of two samples of articles containing the term business ethics (comprising of 100 newspaper articles spread over an 18 -year period from a sample of US and UK newspapers).

Findings: The paper demonstrates increased coverage of sustainability topics within the media over the last 18 years associated with events such as the Rio Summit. Whilst some peaks are seen associated with business ethics scandals, the overall coverage remains at a steady state. There is little apparent use in the media on concepts such as corporate citizenship. The academic community and company ethical codes appear to adopt a wider definition of business ethics more akin to those associated with sustainability, in comparison with the focus taken by the media especially in the US. Coverage demonstrates clear regional bias and contextual analysis of the content of the articles in the UK and US also shows interesting parallels and divergences in the contextual representation of business ethics in the media.

Research limitations/implications: The non-OECD sample is limited due to discrepancies in coverage. More detailed analysis is needed in future work to explore the differences in regional coverage and more detailed analysis of the events triggering the peaks in coverage across the 18-year timeline.

Practical Implications: This study provides insights into the conceptualisation of business ethics $\mathrm{n}$ different regions and over time. This is of value to those working in this field and operating in different regional contexts.

Originality/value: A promising avenue to explore how the evolution of sustainability issues including business ethics can be tracked within a societal context.

Keywords: business ethics, longitudinal, regional, sustainability, Type of Paper: Research paper
\end{abstract}




\section{Introduction}

This special edition challenges researchers to consider business ethics from a longitudinal and evolutionary perspective and to give attention to the durability of ethical values and principles in society at large. This paper presents an analysis of the representation of business ethics within the media as a mechanism to track this evolution over time and within different regional contexts. News reports are an important source of information about society and the textual analysis of these allows the measurement of the importance of key events and concepts (Montes-y-Gomez et al., 2001).

Business ethics is described as part of a 'veritable explosion of concepts that aim to explain what the proper role of business in society should be' that includes terms such as corporate citizenship, corporate social responsibility, and sustainable development (Preuss, 2008). This explosion of terminology is a result of the widening remit of business studies to include social and environmental dimensions alongside the traditional economic concerns.

This paper examines the framing of business ethics over time and in specific contexts as represented by media coverage, as surrogate measure of the penetration of business ethics concepts into society. The specific research objectives are:

- $\quad$ to explore a longitudinal analysis of the relationship between the use of the term business ethics in society and associated concepts such as corporate accountability and citizenship;

- $\quad$ examine the coverage of business ethics from different regional perspectives; and

- $\quad$ analyse the content of business ethics reporting within a US and UK context.

The paper begins by presenting an overview of the historical evolution of business ethics, before considering the role of media coverage in both shaping and representing public opinion and societal norms. An overview of the methodological framework used in this paper is then presented. The paper then examines the findings from the contextual analysis by using two sample sets:

- textual analysis of the frequencies of business ethics and associated terms within a sample of 62 newspapers from around the world over an 18 year period; and

- content analysis of the text of 2 samples (US/UK) of 200 articles on business ethics.

\section{The historical evolution of business ethics}

De George (1987, p.201) argues that the 'history of ethics in business is a long one, going back to the beginning of business'. Early examples include the 1803 code of conduct written by the British medical establishment (Knouse et al., 2007). However, whilst the history of ethics in business is well established, its emergence as an academic discipline is more recent, citing 1985 as a point in history when business ethics 'had become an academic discipline albeit in the process of definition' (De George, 1987, p.203).

Ethical codes for business appear to be influenced by the prevailing ideology of the time (De Knouse et $a l$, 2007). In the early $20^{\text {th }}$ Century this business ideology emphasised religious values in the treatment of employees and directing their conduct in the work environment and private life. Examples include Henry Ford ensuring employees complied with his code of conduct based on his personal religious beliefs and JC Penney's partners pledging honesty, integrity, and moral leadership, which formed a basis of their first ethical code of conduct published in 1913 (Knouse et al., 2007). By the 1950's and 6o's attention had shifted away from influencing the morals of employees and welfare responsibilities, towards managing the risks associated with occupational health and safety. 
By the early 1960's an increasingly legislative climate sought to control the impact of business on society and the environment (Knouse et al. 2007). DesJardins (2007) argues that there are the three spheres of human existence: economics, ecology, and ethics and argues that the integration of these 'must be a part of any legitimate attempt to address the profound challenges of the $21^{\text {st }}$ Century'. This emergence of a 'triple bottom line' approach to the operation of business and the constraints that the ecological environment might place on business is one that has been steadily gaining ground. The warning was posed by Silent Spring (Carson et al., 1962) of the danger that the pesticide industry might pose to natural ecosystems opened the door to those voices that were beginning to question the prevailing paradigm of unrestrained economic growth and the legacy of environmental damage.

The heated debates around the veracity of the claims made in Silent Spring were played out in the media and were an early example of the influence of the media in shaping public response to an environmental or social issue and the resultant impact on the corporate and policy arena. In the late 1970 's the media also presented wide-ranging coverage of the discovery of buried toxic waste under houses and a school in the Love Canal area in the USA, which led to the eventual creation of Superfund. A thirty-year high profile battle between Occidental Petroleum and the residents of Love Canal is detailed by Gibb (1998), with the US EPA successfully suing for \$129 million in restitution in 1995 .

The implication of failure of safety procedures to local communities was emphatically demonstrated by the massive death toll from the chemical disaster at Bhopal disaster of 1984 described by Piasecki (1994, p.24) as the 'environmental equivalent of Pearl Harbor'. This disaster motivated many of the high-risk companies to set procedures into place to manage and mitigate the risks of their manufacturing operations. It was also a clear demonstration of the power of the media to inform society of business failures. At the turn of the century other kinds of business failures were making the headlines - tales of widespread financial mismanagement and corporate fraud at Enron, Tyco, WorldCom, and Adelphia that led to the enactment of the US Sarbanes-Oxley Act of 2002 and greater scrutiny of the financial management of companies.

The Ethics Resources Center (2008) charts this evolution of business ethics from the 1960's onwards as illustrated in table 1. It is clear that business ethics now embraces a wide range of aspects ranging from working conditions, corruption, and fraud through to environmental and social responsibility.

Table 1: The Business Ethics Timeline (adapted from Ethics Resources Center, 2008)

\begin{tabular}{|c|c|c|}
\hline & Ethical Climate & Major Ethical Dilemmas \\
\hline $1960 s$ & $\begin{array}{l}\text { Social unrest. Anti-war sentiment. Employees have an } \\
\text { adversarial relationship with management. Values shift away } \\
\text { from loyalty to an employer to loyalty to ideals. Old values are } \\
\text { cast aside. }\end{array}$ & $\begin{array}{l}\text { Environmental issues. Increased employee - } \\
\text { employer tension. Civil rights issues dominate. } \\
\text { Honesty. The work ethic changes. Drug use } \\
\text { escalates. }\end{array}$ \\
\hline $1970 s$ & $\begin{array}{l}\text { Defence contractors and other major industries riddled by } \\
\text { scandal. The economy suffers through recession. Unemployment } \\
\text { escalates. There are heightened environmental concerns. The } \\
\text { public pushes to make businesses accountable for ethical } \\
\text { shortcomings. }\end{array}$ & $\begin{array}{l}\text { Employee militancy (employee versus } \\
\text { management mentality). Human rights issues } \\
\text { surface (forced labour, sub-standard wages, } \\
\text { unsafe practices). } \\
\text { Some firms choose to cover rather than correct } \\
\text { dilemmas. }\end{array}$ \\
\hline $1980 \mathrm{~s}$ & $\begin{array}{l}\text { The social contract between employers and employees is } \\
\text { redefined. Defence contractors are required to conform to } \\
\text { stringent rules. Corporations downsize and employees' attitudes } \\
\text { about loyalty to the employer are eroded. Health care ethics } \\
\text { emphasized. }\end{array}$ & $\begin{array}{l}\text { Bribes and illegal contracting practices. } \\
\text { Influence peddling. Deceptive advertising. } \\
\text { Financial fraud (savings and loan } \\
\text { scandal). Transparency issues arise. }\end{array}$ \\
\hline $1990 s$ & $\begin{array}{l}\text { Global expansion brings new ethical challenges. There are major } \\
\text { concerns about child labour, facilitation payments (bribes), and } \\
\text { environmental issues. The emergence of the Internet challenges } \\
\text { cultural borders. Global Sullivan Principles (1999) }\end{array}$ & $\begin{array}{l}\text { Unsafe work practices in third world countries. } \\
\text { Increased corporate liability for personal } \\
\text { damage (cigarette companies, Dow Chemical, } \\
\text { etc.) Financial mismanagement and fraud. }\end{array}$ \\
\hline
\end{tabular}




\begin{tabular}{|l|l|l|}
\hline \multirow{2}{*}{$2000 s$} & Ethical Climate & Major Ethical Dilemmas \\
& $\begin{array}{l}\text { Unprecedented economic growth is followed by financial } \\
\text { failures. Ethics issues destroy some high profile firms. Personal } \\
\text { data is collected and sold openly. Hackers and data thieves } \\
\text { plague businesses and government agencies. Acts of terror and } \\
\text { aggression occur internationally. }\end{array}$ & $\begin{array}{l}\text { Cyber crime. Privacy issues (data mining) } \\
\text { FN Global Compact adopts 10th principle against corruption (2004) } \\
\text { corruption. Loss of privacy - employees versus } \\
\text { employers. Intellectual property theft. The role } \\
\text { of business in promoting sustainable } \\
\text { development. } \\
\text { Corruption (2003); }\end{array}$ \\
\hline
\end{tabular}

This evolution of business ethics into a multifaceted set of responsibilities is also clear when we examine some specific business ethics codes. For instance the oil and gas exploration company Soco International state:

'Before embarking on any course of action, we need to ask ourselves these questions: Is anyone's life, health or safety, or the environment endangered by the action? Is it legal? Does it feel fair and honest? Does it compromise trust or integrity? Could I justify it to the public?' (Soco, 2008)

SSAB also present a multifaceted code of business ethics:

'SSAB is committed to creating value for its stakeholders and to building relationships based upon respect, responsibility and excellence with its employees, customers, consumers, shareholders and other business partners - and to do so in a socially and environmentally responsible manner. Achieving this requires strong financial performance, environmental stewardship and social commitment.'(SSAB, 2008)

When we consider the Fortune 500 list of the world's top companies we can also see an integration of economic, environmental and social principles under the umbrella of 'ethical conduct'. A segment of Wal-Mart's principles demonstrates this:

'The vision of Wal-Mart's Ethical Standards Program (ESP) is sourcing ethically through a socially responsible program. The program exists to strengthen the implementation of positive labor and environmental practices in factories, to bring opportunities for a better life in the countries where merchandise for sale by Wal-Mart is sourced, and to verify factory compliance with our Standards for Suppliers' (Wal-Mart, 2008).

This statement also demonstrates another facet of the widening concept of business ethics. Whereas the early history of ethical business conduct focused on employees and their behaviour, the scope has now widened to use ethical codes of conduct to address the interaction between a business, employees, local community, and their supplier network. The impact of the world largest companies in shaping values and disseminating their ethical codes is potentially vast. The Fortune 500's top 15 companies generate a revenue of $\$ 4.2$ trillion, the equivalent of $7.7 \%$ of the world's GDP surpassing every county in the world except the US (13.8 trillion) and Japan ( 4.4 trillion), they directly employ 4.27 million people and indirectly affect many millions more through their economic multiplier effect (Fortune, 2008).

An analysis of 150 years of US company codes of business ethics concluding that such codes 'directly reflect the values prevailing in business at that time' and note the influence of societal values (Knouse et al., 2007, p. 104). Such societal values are made up of individual belief systems, which are an ideological product of individual experiences and culture (Corbett 2006, p.12), constrained by moral and legal boundaries. Values, beliefs, attitudes, and behaviours combine to produce a set of societal norms. The social norms for how a business should operate are influenced by internal factors such founder ideals (Ogbonna and Harris, 2001) but are more commonly a reflection of the prevailing societal climate. 'Public concern' is identified as one of three key external drivers that influences the extent and nature of corporate environmental behaviour, alongside regulation and competitive forces (Banerjee et al., 2003). The content and intensity of public opinion has been identified by Vogel (1993) as a crucial factor 
influencing the development of national environmental policies in the United States. The widespread emergence of concern over the impact of climate change is clearly linked to high levels of publicity surrounding the publication of 'An Inconvenient Truth' in 2006, which built on a large pre-history of awareness building by activists and within the policy agenda.

Some of the major events that may have influenced the coverage of business ethics and sustainability are detailed in table 2. Montes-y-Gomez et al. (2001) argue that examining coverage of events such as these can provide information of general societal trends and associations.

Table 2: Major ethical/environmental events from 1984-2008

\begin{tabular}{|l|l|l|}
\hline Bhopal chemical accident in India & Dec & 1984 \\
\hline Chernobyl nuclear accident & April & 1986 \\
\hline Brundland report released & 1987 \\
\hline Exxon Valdez oil spill in Alaska & March & 1989 \\
\hline Earth Summit in Rio (UNCED) & June & 1992 \\
\hline Execution of Ken Saro Wiwa in Nigeria & Nov & 1995 \\
\hline Framework convention on climate change at Kyoto & Dec & 1997 \\
\hline UN Millennium Summit and Millennium Goals & Sept & 2000 \\
\hline Enron file for bankruptcy & Dec & 2001 \\
\hline Adelphia's stock suspended on NASDAO & May & 2002 \\
\hline WorldCom financial scandal erupts & July & 2002 \\
\hline Sarbanes-Oxley Act of 2002 & July & 2002 \\
\hline World Summit on Sustainable Development in Johannesburg & August & 2002 \\
\hline Wal-Mart speech by CEO announcing moves towards Sustainability & October & 2005 \\
\hline Hurricane Katrina and New Orleans floods & August & 2005 \\
\hline Stern Review on economics of climate change released & October & 2006 \\
\hline Inconvenient Truth released & May & 2006 \\
\hline Al Gore and IPCC awarded Nobel Peace prize & October & 2007 \\
\hline Live Earth concerts to raise awareness of climate change & July & 2007 \\
\hline
\end{tabular}

\section{The role of media coverage in shaping public opinion and societal norms}

Norris (2001) states that within a representative democratic society the media serves three key functions: as a civic forum; a mobilizing agent for change/action; and as a watchdog overseeing behaviour. The role the media plays in public agenda-setting includes passively transmitting 'public opinion', or actively shaping the public agenda (for example Lewis, 2000; and Valenti, 2003). Thus an analysis of media coverage in a given societal context provides insights into the level of public 'promotion' of a specific issue and allows an examination of how this has shifted contextually and longitudinally.

It should be noted that the relationship between 'public opinion' and the extent and nature of media coverage is also mediated and moderated by a number of variables. These variables include the political orientation of a newspaper, its ownership structure, and language medium. Differences between the representations of specific issues have also been noted in newspapers of different nationality. A qualitative analysis of German and Dutch newspapers demonstrated significance differences between the coverage of the same issue (Bijsmans and Altides, 2007). Similarly, Brossard et al. (2004) found significant differences between French and US newspaper coverage of climate change-related news stories. Whilst it cannot be argued that there is a direct correlation between coverage of a specific event and change in behaviour there is no doubt that media coverage can influence the level of awareness of specific issues. This media coverage could act as a general barometer of the contextual framing of issues such as business ethics, sustainable development, corporate citizenship and accountability within society. 


\section{Methodology}

The data collection can be described as a basic text mining technique (Hearst 1997, 1999; Manning and Schütze 2002) or knowledge discovery from textual databases (Feldman and Dagan, 1995), and is based in the field of data mining from knowledge discovery in databases (Fayyad et al., 1996; Tan, 1999). Text mining refers to the process of generating patterns or knowledge from unstructured or semi-structured text (Feldman and Sanger, 2007; Tan, 1999). This study searched for specific words contained in a sample of documents (after Lent et al., 1997).

In the first stage of the data collection a longitudinal analysis of the coverage of business ethics related concepts was explored, through a text mining application covering the period January 1990 - July 2008. A sample of 62 national newspapers from 21 countries was used ( 222 months), restricted to those published in the English language to prevent errors from translation of terms affecting the data collection.

When newspapers were not accessible through the databases over the full period of analysis, they were included into the sample from the first full month they became available. Selection criteria included circulation, area of circulation and, if possible, private ownership. In terms of area of circulation, we aimed for newspapers that were not predominantly local or regional in scope and therefore at least to a certain extent reflected their national public agendas, respectively.

The selection process aimed to create a sample that was as geographically diverse as possible, especially concerning non-OECD countries but availability from these regions was restricted (table 3). In some cases such as Russia, Japan, China (Hong Kong) or South Africa, the analysis was restricted to national newspapers that published in the English language.

Table 3: Distribution of newspaper coverage in sample by country

\begin{tabular}{|l|r|l|r|l|r|}
\hline UK & 9 & Ireland & 3 & Pakistan & 1 \\
\hline south Africa & 8 & Singapore & 2 & Nepal & 1 \\
\hline USA & 7 & Russia & 2 & Malaysia & 1 \\
\hline Australia & 7 & Korea & 2 & KG & 1 \\
\hline Canada & 5 & India & 2 & Israel & 1 \\
\hline New Zealand & 3 & Thailand & 1 & Czech & 1 \\
\hline Japan & 3 & Philippines & 1 & china & 1 \\
\hline
\end{tabular}

In the first stage the results of the data mining process were converted into frequency tables and a base unit of analysis, the monthly average number of hits (articles containing the search term) per newspaper issue, was calculated. This allows for comparison of different newspapers, as it takes into account that some newspapers are released daily, whereas others are only released on weekdays. Therefore a sample frequency of 0.1 for 'business ethics' represented a probability of $10 \%$ for that month that any newspaper bought would have at least one article that mentioned the term 'business ethics' within it.

$$
\text { Hitsper/ssue }=\frac{\text { (Total Number of monthly Hits/Number of DaysinMonth })}{(\text { Issues per Week } / 7)}
$$


There were minor issues regarding the accuracy and comparability of search terms: as the term 'sustainability' carries a broader meaning than e.g. 'corporate citizenship', which has in turn implications for the total level of word frequencies. However, the longitudinal analysis carried out in this study allows for the identification of long-term trends and regional deviations, which are not affected by these characteristics of the search terms used. Furthermore, irregularities in the search reports (such as misspelling of terms or the title of a publication, or changes in date format) led to slight errors in data transformation. An error of $1 \%$ was tolerated; larger errors were corrected through reiterative adjustment of the text-mining tool.

Another issue was the incremental increase of newspapers included into the analysis due to improved data availability in the latter stages of the period under review. For example, the majority of South African newspapers were only included in the analysis as of July 2006. However, we decided to include these newspapers as of the date they became available in order to increase regional diversity of the sample. Finally, a factor that may have influenced the results is syndication. However, it is argued that due to the sample size and regional diversity the impact of syndication remains limited.

The second stage of the data collection used the sample of US and UK newspapers, over the 18 year period, where the actual articles that contained the phrase 'business ethics' were identified (approximately 1000 in each sample). These samples were designed to capture the 'background' noise of business ethics publications (i.e. how business ethics has generally been contextualised between 1990 and 2008) rather than examine specific peaks in coverage. The text analysis tool Textanz ${ }^{1}$ was used to perform term counts on news corpora. From a list of chronologically sorted articles, each fifth article was downloaded as full-text document and compiled to a plain text file for each country containing 200 articles. News items from different sources were aggregated in different plain text files, according to the specific analysis to be performed. The Textanz tool was then used, with its default settings, to produce simple counts of the occurrences all (possibly compound) terms from the text files. All terms that occurred at least 10 times in either one of the two samples were screened, and all terms of interest in the context of a contextualisation of business ethics were then identified. Their corresponding counts (number of 'occurrences') were used for the subsequent analysis.

Crude counting of the occurrences of relevant terms in a corpus of news items can be a good indication of the coverage dedicated to a given topic over time and space. It is easy to perform and does not require complex tools. In order to account for differences in the distribution of terms over time, a weighting factor is introduced that compares the distribution in the sample to a standard uniform distribution. As the focus of the analysis rests on the general contextualisation of business ethics over time, more weight should be assigned to ten occurrences of a given term in 5 different news items in a certain time period than to ten occurrences of the same term in a single news item over another time period of the same length. The above- mentioned limitations regarding specific characteristics of terms analysed as well as general limitations to the analysis of newspaper articles also apply for this second stage of the analysis.

\section{Longitudinal analysis of business ethics and associated terms}

The literature suggests an evolution of business ethics from a narrowly focused topic within the business arena towards a more holistic view of corporate responsibility that includes the three pillars of sustainability - the triple bottom line of economic, environmental, and social. This is certainly borne out by the content of many of the Fortune 500 ethical business codes of conduct as discussed earlier. Figure 1 explores the usage of the term business ethics and associated concepts within the media, across the total sample of 62 newspapers from around the world. 


\section{Concepts - Hits per Newspaper Issue (Monthly Averages)}

62 English Language Newspapers

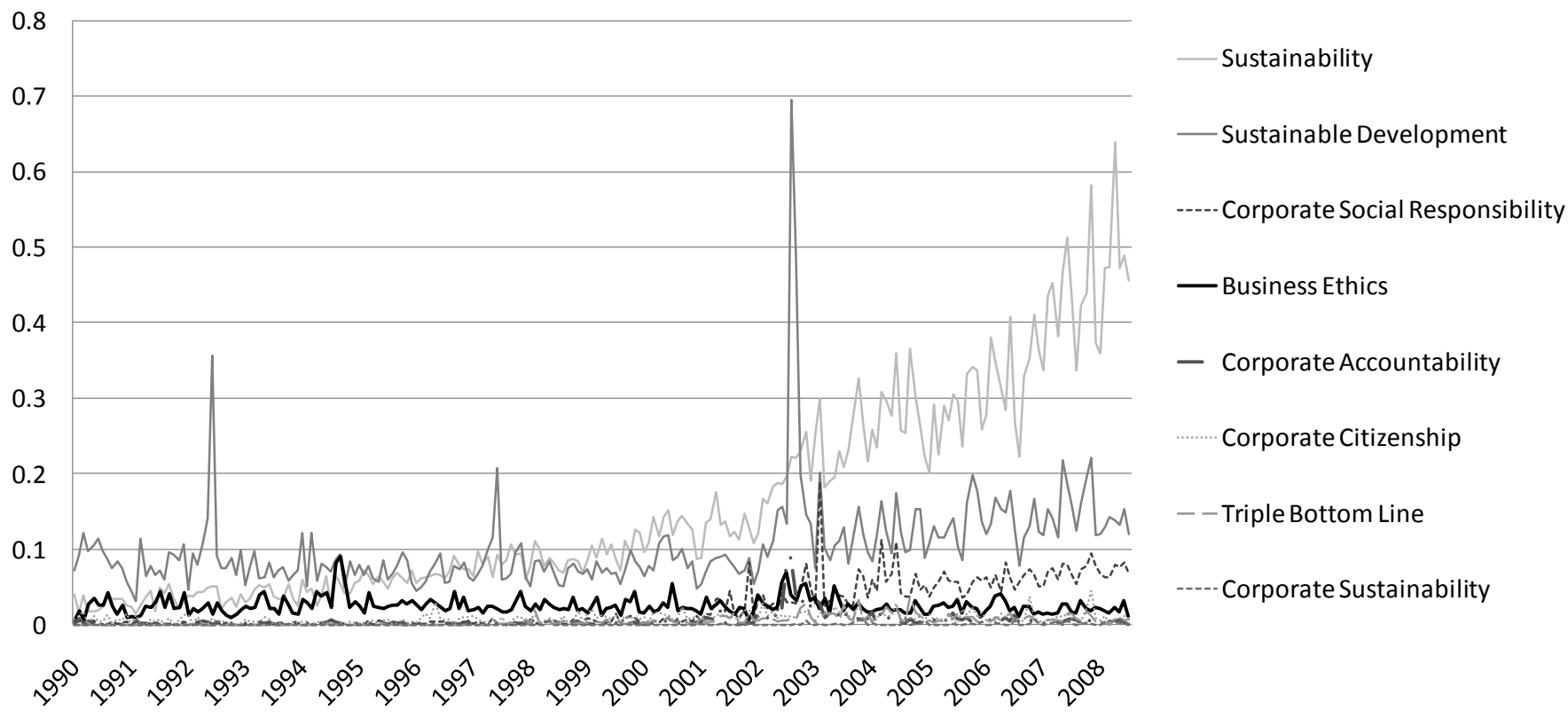

Figure 1: Longitudinal trends in coverage of business ethics and associated terms

This longitudinal analysis illustrated in figure 1 suggests a number of important findings. There is a significant increase in the media coverage of sustainability-related concepts since 1990, as indicated by the 'sustainability' trend line. Sustainable development is a phrase that demonstrates three large peaks in 1992, 1997/98 and 2002/03 which are associated with the Earth Summit in Rio de Janeiro in 1992, Kyoto 1997 and Johannesburg 2002 which may have contributed to the general increase in the use of the term sustainability. However business ethics, corporate citizenship and corporate accountability all demonstrate much lower levels of usage. With the exception of the peak in 1995, and late 2002 the coverage of business ethics remains below 0.06. In other words at any point in time less than 6 newspapers in every 100 mention business ethics per month. This trend has remained fairly constant over time. The peak in 1995 is associated with controversy around the Bodyshop, Harrods and bribery within the UK government, focussed mostly in the UK. None of these issues made an impact by themselves but formed a cluster of coverage that influenced the overall trend line. The peak in mid 2002 is related to the Enron, WorldCom, Adelphia scandals, and coverage of the Sarbanes-Oxley Act and focused mostly in the US. There is little usage of the terms corporate accountability and citizenship, suggesting that these remain largely academic terms that have failed to penetrate societal consciousness. However, one exception regarding corporate accountability is a distinct peak in 2003 as a result of the introduction of corporate accountability regulation in the US. Corporate social responsibility (CSR) is a term that reached parity with business ethics in the late 1990's. The clear peak in CSR coverage in 2003 is related to a special edition of the Observer newspaper but unlike business ethics CSR appears to be demonstrating an upward trajectory. This suggests that, within the popular media at least, business ethics might remain narrowly focussed around financial mismanagement and the term CSR encompasses the broader sustainability dimensions. This suggests an interesting avenue for future work - that explores the relationship (and intersections) between what is considered as CSR and business ethics, as interpreted by the media and content of articles), by the academic community, and within organisational codes of practice. 


\section{Business Ethics versus Aggregated Concepts - Hits per NP Issue (Monthly Averages)}

(CSR / Corporate Citizenship / Corporate Accountability / Corporate Sustainability / TBL)

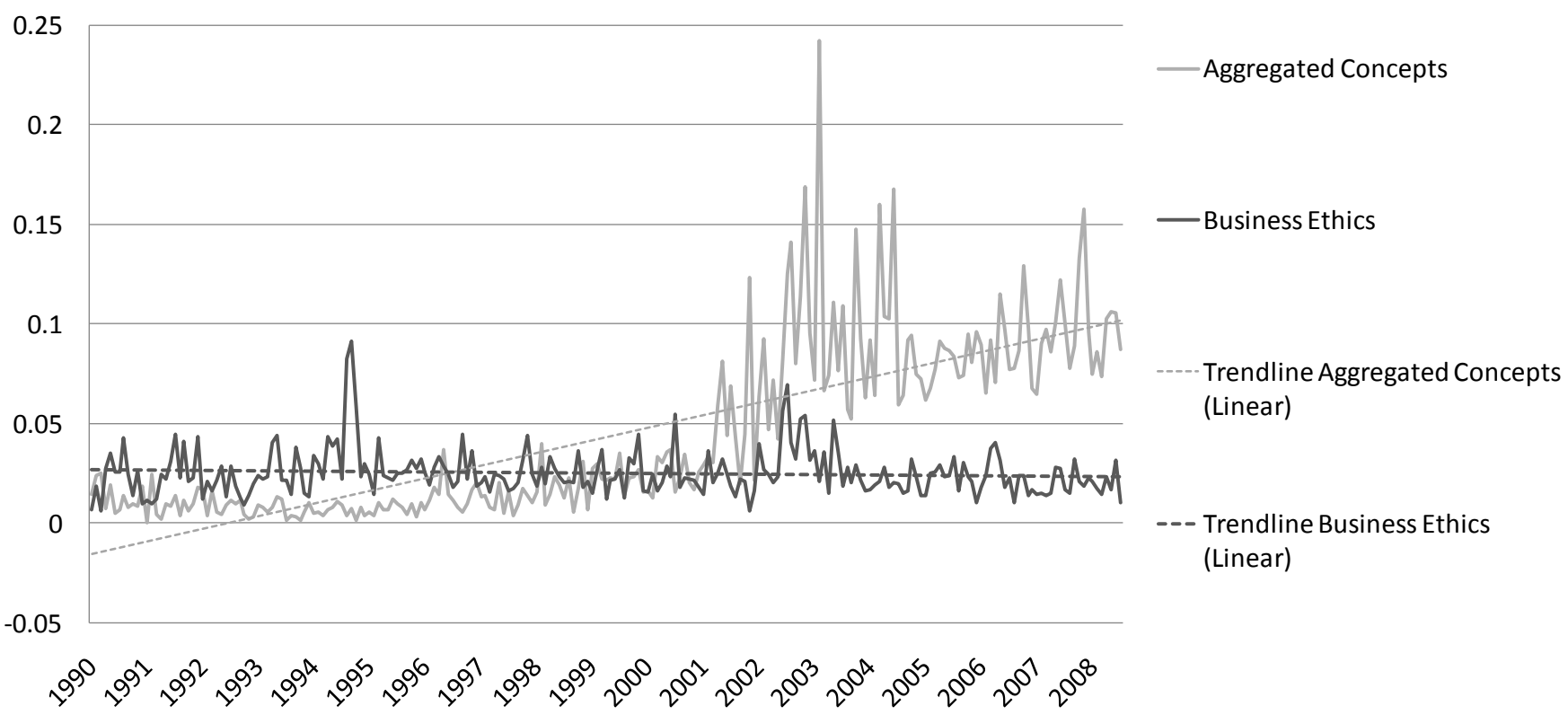

Figure 2: Comparison of business ethics and associated terms

Figure 2 illustrates a linear longitudinal trend line for business ethics compared with an aggregate measure of the other associated concepts. Business ethics demonstrates a clearly linear distribution over time, only peaking when corporate scandals such as Enron or WorldCom erupt. However, the aggregated concepts (citizenship, accountability, CSR, triple bottom line, corporate sustainability) show a clear upward trajectory. Interestingly in the early 1990's business ethics was the dominant concept but as the coverage of CSR increased we currently see an average trend line in coverage of approximately 0.03 for business ethics and 0.13 for CSR.

\section{Contextualising business ethics from a regional perspective}

The second objective of this paper was to explore the coverage of business ethics from different regional contexts. The previous discussion focuses on a sample of (English language) newspapers from across the world and considers the total level of coverage of business ethics. Authors such as Bijsmans and Altides (2007) and Brossard et al. (2004) have noted regional differences in the coverage of the same ethical issues. Rossouw (2002) also suggests that different parts of the world consider business ethics differently, suggesting that African businesses do not consider ethics to be an integral part of what they do. Rossouw (2002) suggests a range of unethical business practices that, whilst not unique to Africa, appear to be found in African business practice such as fraud, unfair dismissal of those with HIV-AIDS, race/gender inequalities, nepotism, and neglect of safety of employees. He further states that 'one way of excusing the neglect of ethics in business is by circulating views in society that treat such unethical conduct as 'normal business" (Rossouw, 2002, p.12). We would argue that the media is one of the key channels through which such messages are circulated. Therefore this section of the paper explores the coverage of business ethics by region. We do not consider at this stage the actual content of the business ethics coverage, only the relative presence/absence from a regional perspective. 


\section{Business Ethics - Hits per NP Issue (Yearly Averages)}

(selected countries)

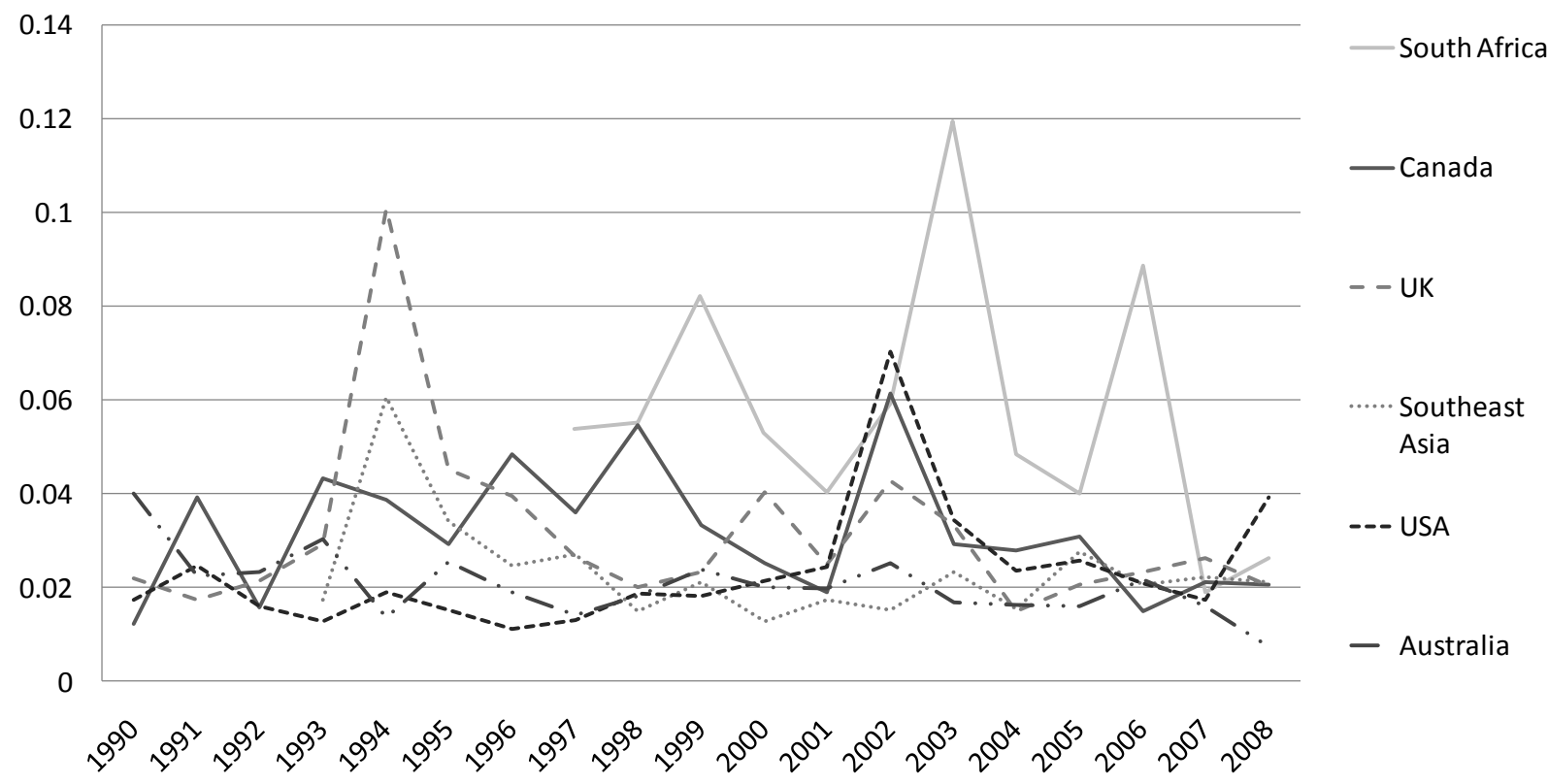

Figure 3: Regional coverage of business ethics

Figure 3 details the 'smoothed' yearly averages and suggests that relative levels of coverage of business ethics display clear regional differences. On the whole coverage is greatest in Africa; however this dataset represents only between two and eight (as of July 2008) newspapers from South Africa and therefore may demonstrate some bias. Future studies should explore this region in more detail especially in light of the commentary on business ethics in Africa by Rossouw (2002). Certain peaks are echoed by different regions - such as the 2002/3 peak associated with Enron and others, which is seen in UK, Canada, US and Australia but not really echoed in Southeast Asia or Africa. Overall coverage at this point in time was highest in the US and Canada. Whereas the peak in 1995 associated with the three UK incidents was highest in the UK and Southeast Asia (with the links to Hong Kong associated with the scandal), and minimal coverage in the US, Australia or Canada.

Overall, average trends in business ethics coverage up to mid-2008 appear to be emerging that are relatively low and in some cases getting lower. In Australia business ethics had the strongest coverage at the start of the dataset in 1990 (approximately 0.04) but this is currently trending downwards towards 0.01 in 2008. Coverage is below 0.04 for all regions in 2008 suggesting that business ethics is mostly discussed in relation to specific events rather than as a broader concept that is discussed on a regular basis. Rather than demonstrating any form of 'punctuated equilibrium' (after Romanelli and Tushman, 1994) where the event would trigger an evolution in the level of coverage to a new baseline, coverage appears to be event focussed, reaching a peak in coverage, and then returning to a static level. The aspect of punctuated equilibrium is arguably demonstrated in the trend lines associated with sustainability presented in figure 1 but not within the business ethics arena.

Figure 3 suggests that some ethical business issues have great regional impacts. Future work should explore regional differences in more detail to identify the specific issues pertinent to that locale and compare these with the ethical policies of companies that operate in these regions.

In figure 4 the distribution of business ethics over time is compared with the aggregate of all the other concepts (including CSR) for the seven US newspapers included in the sample. Here we see all coverage 
was below 0.05 until 2001 with business ethics mostly dominating what little coverage there was. The flurry of coverage in 2002/3 was related to the financial scandals with business ethics reaching a peak of 0.15 and the aggregate (which included accountability and CSR) reaching a corresponding but higher peak of 0.35 . From 2002 onwards the aggregated terms have a higher level with a clear separation between the peaks suggesting that those issues covered by business ethics are clearly separate from those covered under the aggregate terms.

Business Ethics versus aggregated other concepts - Hits per NP Issue (Monthly Averages) (USA)

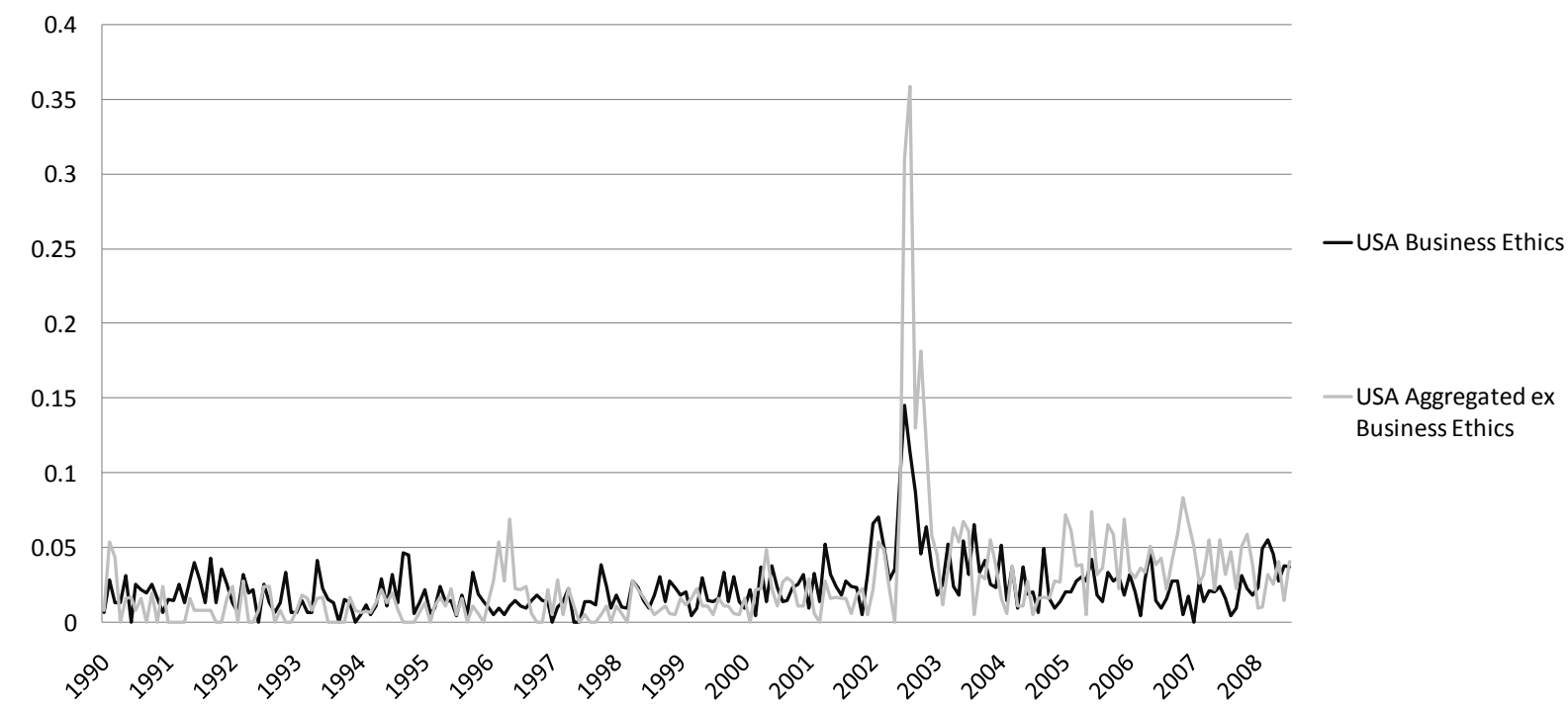

Figure 4: Coverage of business ethics and aggregated concepts in USA

The disconnect between business ethics and the associated aggregate terms is even clearer in the nonUS sample ( 55 newspapers) presented in figure 5 . Here again business ethics remained the dominant theme until 2000. After 2000 the aggregate clearly trends upwards, typically remaining above 0.1 and reaching approximate highs of 0.3 and 0.6 , whereas business ethics coverage remains below 0.05 in most cases with a few peaks around 0.1. Thus comparing figure 4 and 5 we suggest that there is a rise in the level of the aggregate terms (mostly comprising of the influence of CSR) but only in non-US sample. 
Business Ethics versus aggregated other concepts - Hits per NP Issue (Monthly Averages) (total ex USA)

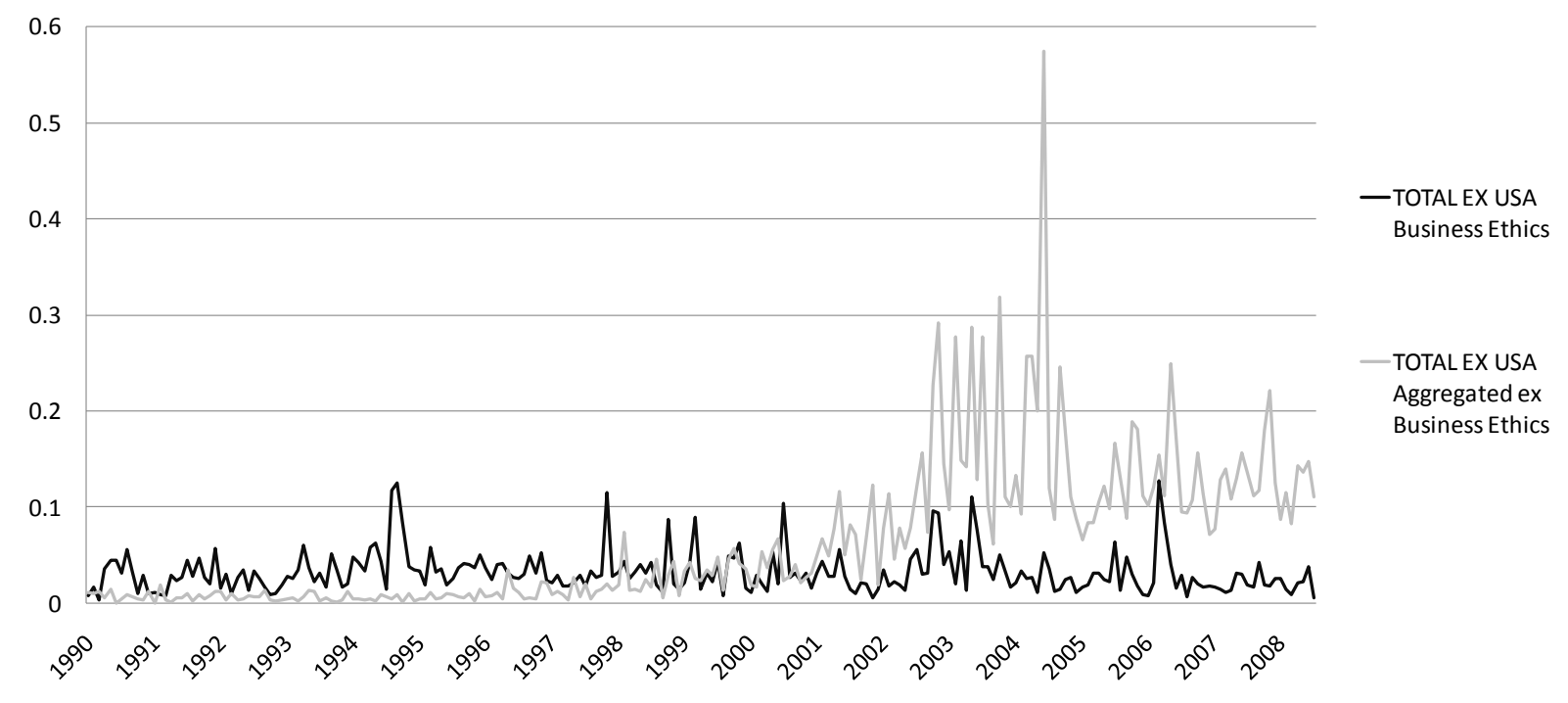

Figure 5: Coverage of business ethics and aggregated concepts in UK

In figure 6 we explore the differences between coverage of business ethics in a UK and US sample. Up to2001 coverage of business ethics was higher in the UK than the US. After 2002 the difference between the two groups appears reduced. Interestingly the peaks associated with Enron and other financial scandals are clear but there appears to have been no lasting legacy in the levels of coverage suggesting business ethics may be dominated by issue-attention-cycles (after Downs, 1972). There are different peaks occurring at different points in time that may be linked to regional events. This suggests that an investigation of the content of business ethics is necessary to see if there are specific differences in the focus of coverage, as explored in the next section.

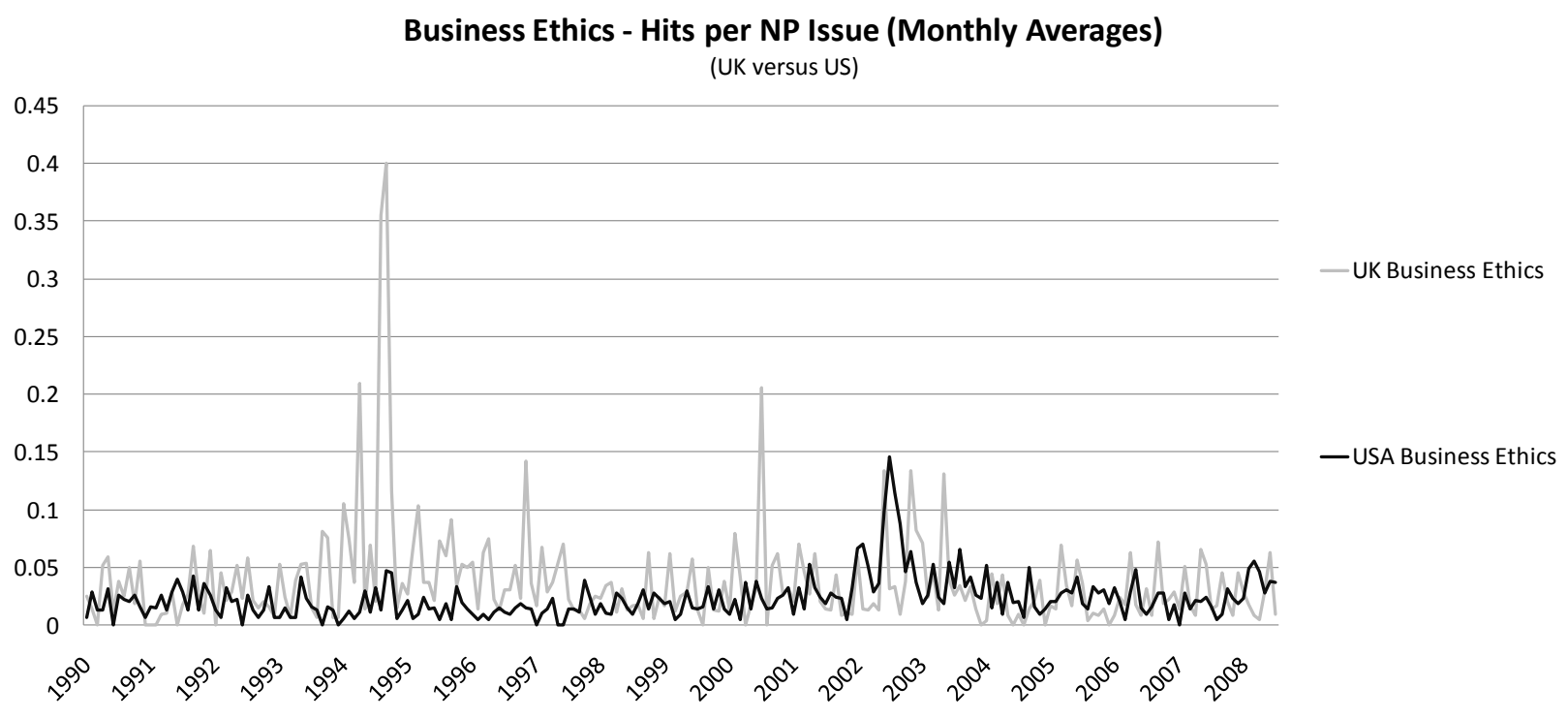

Figure 6: Comparison of UK and USA coverage of business ethics 
In this section we are interested in the overall context of business ethics coverage in the UK and US sample rather than the coverage of the specific events. Therefore a selection of articles spread over the 18-year period is analysed using a textual analysis programme. For each sample, 200 chronologically sorted articles were extracted as full-text documents and compiled to a single text file. The text files were subsequently analysed with the text mining tool Textanz which provided the number of occurrences of each term as well as the standard deviation $(\sigma)$ of its distribution. An initial examination of a list of terms occurring at least ten times in either of the two samples of text generated the list of key terms. The crude counts of these key terms presented in the columns ' $\mathrm{O}_{\cup K}$ ' and ' $\mathrm{O}_{\mathrm{Us}}$ ' of table 4 .

$O_{i} \quad$ Number of Occurrences in sub sample

$\boldsymbol{W}_{\boldsymbol{i}} \quad$ Weighting factor for term in sub sample

$O_{i}$ adj Distribution-adjusted number of occurrences in sub sample do Occurrences differential

In order to account for differences in distribution over time, a weighting factor $\mathrm{W}_{\mathrm{i}}$ for each measurement was calculated and multiplied with the term count, resulting in the adjusted term count $\mathrm{O}_{i}$ adj. This weighting factor indicates the deviation of a key term's distribution over time from a standard uniform distribution, measured as the ratio of its standard deviation over the standard deviation of a standard uniform distribution:

$$
W_{i}=\left(1-\left|1-\frac{\sigma}{\frac{\text { Total Number of Characters }}{2 \sqrt{3}}}\right|\right)
$$

A weighting factor of 1 indicates a perfectly equal distribution over time, whereas a weighting factor of close to zero indicates a very unequal distribution. For example, although the key term 'tobacco' appears 23 times in the UK sample and only 11 times in the US sample, the adjusted term counts are similar. This reflects a cluster of media coverage in the UK of British American Tobacco's donation to the University of Nottingham to found an international centre for business ethics in the year 2001, which resulted in a higher overall number but compensated for when adjusted values are used.

In the third step of the calculation, the occurrence differential $d O$ is calculated, describing the similarity of the adjusted number of occurrences of a key term in the two sub samples. A value tending towards zero indicates a strong similarity between the US and UK samples in terms of their adjusted number of occurrences.

Correspondingly, the closer the factor to $1(-1)$, the greater the differential between the two samples. A positive value indicates that there were a higher adjusted number of occurrences in the UK and a negative value that the adjusted number of occurrences was highest in the US sample. 
Table 4: Contextual analysis of UK and US newspaper articles containing the term 'business ethics' $(n=400)$.

\section{UK \\ $O_{U K} \quad W_{U K} \quad O_{U K}$ adj}

Stakeholders

government(s)/governmental shareholder society/societies/societal

public/publicly

consumer(s)

employee(s)

worker(s)

community(ies)

investor(s)

union $(\mathrm{s})^{\star *}$

Topics

\begin{tabular}{|r|r|r|}
\hline $\mathbf{1 1 5}$ & 0.9471 & 108.9213 \\
\hline $\mathbf{4 9}$ & 0.9706 & 47.5605 \\
\hline $\mathbf{4 5}$ & 0.8566 & 38.5479 \\
\hline $\mathbf{1 3 6}$ & 0.9036 & 122.8925 \\
\hline $\mathbf{5 3}$ & 0.9629 & 51.0311 \\
\hline $\mathbf{6 2}$ & 0.8640 & 53.5697 \\
\hline $\mathbf{3 7}$ & 0.8660 & 32.0407 \\
\hline $\mathbf{6 7}$ & 0.9433 & 63.2006 \\
\hline $\mathbf{5 2}$ & 0.8923 & 46.3978 \\
\hline $\mathbf{2 4}$ & 0.9065 & 21.7567 \\
\hline
\end{tabular}

global warming/climate change

tobacco

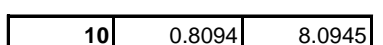

oil

weapon(s)s/arms

chemical

social responsibility sustainable/sustainability environmental(ly)

human right(s)

Instruments

\begin{tabular}{|r|r|r|}
\hline $\mathbf{2 3}$ & 0.4239 & 9.7507 \\
\hline $\mathbf{5 8}$ & 0.9718 & 56.3646 \\
\hline $\mathbf{5 1}$ & 0.8116 & 41.3909 \\
\hline $\mathbf{1 9}$ & 0.8115 & 15.4188 \\
\hline $\mathbf{2 8}$ & 0.9776 & 27.3737 \\
\hline $\mathbf{2 2}$ & 0.6283 & 13.8237 \\
\hline $\mathbf{7 6}$ & 0.8327 & 63.2870 \\
\hline $\mathbf{2 4}$ & 0.8808 & 21.1394 \\
\hline
\end{tabular}

\begin{tabular}{r|r|r|r|} 
& & & \\
principle(s) & $\mathbf{2 2}$ & 0.7664 & 16.8617 \\
\cline { 2 - 4 } standard(s) & $\mathbf{7 9}$ & 0.9469 & 74.8083 \\
\cline { 2 - 4 } codes(s) & $\mathbf{6 2}$ & 0.8871 & 55.0001 \\
\cline { 2 - 4 } guideline(s) & $\mathbf{4}$ & 0.5947 & 2.3787 \\
\cline { 2 - 4 } law(s) & $\mathbf{7 9}$ & 0.8044 & 63.5512 \\
\cline { 2 - 4 } regulation(s) & $\mathbf{1 2}$ & 0.9608 & 11.5294 \\
\cline { 2 - 4 } reporting & $\mathbf{1 2}$ & 0.9565 & 11.4775 \\
\cline { 2 - 4 }
\end{tabular}

Financial (Mis-) management

corrupt(ion)

\begin{tabular}{|l|r|r|}
\hline $\mathbf{3 7}$ & 0.9399 & 34.7748 \\
\hline $\mathbf{2 8}$ & 0.9806 & 27.4567 \\
\hline
\end{tabular}

fraud(ulent)

crime

(corporate) governance accountable/accountability

transparent/transparency

\begin{tabular}{|r|r|r|}
\hline $\mathbf{2 8}$ & 0.9806 & 27.4567 \\
\hline $\mathbf{7 9}$ & 0.8268 & 65.3147 \\
\hline $\mathbf{1 7}$ & 0.9497 & 16.1441 \\
\hline $\mathbf{1 4}$ & 0.6399 & 8.9582 \\
\hline $\mathbf{1 3}$ & 0.7681 & 9.9847 \\
\hline $\mathbf{3 2}$ & 0.9345 & 29.9049 \\
\hline
\end{tabular}

USA

$O_{\text {US }} \quad W_{\text {US }} \boldsymbol{O}_{\text {us }}$ adj

\begin{tabular}{|r|r|r|}
\hline 124 & 0.9745 & 120.8433 \\
\hline $\mathbf{5 3}$ & 0.8543 & 45.2784 \\
\hline $\mathbf{4 6}$ & 0.9422 & 43.3395 \\
\hline $\mathbf{1 6 6}$ & 0.9777 & 162.2924 \\
\hline $\mathbf{4 9}$ & 0.9018 & 44.1892 \\
\hline $\mathbf{1 8 2}$ & 0.9454 & 172.0714 \\
\hline $\mathbf{7 7}$ & 0.5336 & 41.0884 \\
\hline $\mathbf{9 2}$ & 0.9792 & 90.0821 \\
\hline $\mathbf{8 2}$ & 0.8889 & 72.8923 \\
\hline $\mathbf{2 1}$ & 0.9626 & 20.2144 \\
\hline
\end{tabular}

\begin{tabular}{|r|r|r|}
\hline $\mathbf{7}$ & 0.2922 & 2.0454 \\
\hline $\mathbf{1 1}$ & 0.9802 & 10.7820 \\
\hline $\mathbf{4 0}$ & 0.7322 & 29.2869 \\
\hline $\mathbf{2 0}$ & 0.8684 & 17.3683 \\
\hline $\mathbf{8}$ & 0.7115 & 5.6920 \\
\hline $\mathbf{9}$ & 0.9053 & 8.1481 \\
\hline $\mathbf{2 8}$ & 0.8050 & 22.5411 \\
\hline $\mathbf{2 7}$ & 0.8936 & 24.1283 \\
\hline $\mathbf{2}$ & 0.8825 & 1.7649 \\
\hline
\end{tabular}

\begin{tabular}{|r|r|r|}
\hline $\mathbf{1 7}$ & 0.8217 & 13.9686 \\
\hline $\mathbf{8 2}$ & 0.7715 & 63.2646 \\
\hline $\mathbf{6 9}$ & 0.8476 & 58.4868 \\
\hline $\mathbf{1 1}$ & 0.8713 & 9.5846 \\
\hline $\mathbf{1 5 0}$ & 0.9805 & 147.0804 \\
\hline $\mathbf{3 1}$ & 0.9531 & 29.5474 \\
\hline $\mathbf{7}$ & 0.6859 & 4.8013 \\
\hline
\end{tabular}

\begin{tabular}{|r|r|r|}
\hline $\mathbf{1 7}$ & 0.9572 & 16.2731 \\
\hline $\mathbf{5 0}$ & 0.9714 & 48.5722 \\
\hline $\mathbf{6 3}$ & 0.9587 & 60.3985 \\
\hline $\mathbf{1 1}$ & 0.6792 & 7.4709 \\
\hline $\mathbf{2}$ & 0.0631 & $1.0000^{*}$ \\
\hline $\mathbf{2}$ & 0.0004 & $1.0000^{*}$ \\
\hline $\mathbf{4 2}$ & 0.9190 & 38.5969 \\
\hline
\end{tabular}

COMPARISON

$O_{U K} / O_{U K+U S} O_{U S} / O_{U K+U S} d O^{* * *}$

\begin{tabular}{|r|r|r|}
\hline 0.4741 & 0.5259 & $-\mathbf{0 . 0 5 2}$ \\
\hline 0.5123 & 0.4877 & $\mathbf{0 . 0 2 5}$ \\
\hline 0.4707 & 0.5293 & $\mathbf{- 0 . 0 5 9}$ \\
\hline 0.4309 & 0.5691 & $\mathbf{- 0 . 1 3 8}$ \\
\hline 0.5359 & 0.4641 & $\mathbf{0 . 0 7 2}$ \\
\hline 0.2374 & 0.7626 & $\mathbf{- 0 . 5 2 5}$ \\
\hline 0.4381 & 0.5619 & $\mathbf{- 0 . 1 2 4}$ \\
\hline 0.4123 & 0.5877 & $\mathbf{- 0 . 1 7 5}$ \\
\hline 0.3889 & 0.6111 & $\mathbf{- 0 . 2 2 2}$ \\
\hline 0.5184 & 0.4816 & $\mathbf{0 . 0 3 7}$ \\
\hline
\end{tabular}

\begin{tabular}{|r|r|r|}
\hline 0.7983 & 0.2017 & $\mathbf{0 . 5 9 7}$ \\
\hline 0.4749 & 0.5251 & $-\mathbf{0 . 0 5 0}$ \\
\hline 0.6581 & 0.3419 & $\mathbf{0 . 3 1 6}$ \\
\hline 0.7044 & 0.2956 & $\mathbf{0 . 4 0 9}$ \\
\hline 0.7304 & 0.2696 & $\mathbf{0 . 4 6 1}$ \\
\hline 0.7706 & 0.2294 & $\mathbf{0 . 5 4 1}$ \\
\hline 0.3801 & 0.6199 & $\mathbf{- 0 . 2 4 0}$ \\
\hline 0.7240 & 0.2760 & $\mathbf{0 . 4 4 8}$ \\
\hline 0.9229 & 0.0771 & $\mathbf{0 . 8 4 6}$ \\
\hline
\end{tabular}

\begin{tabular}{|r|r|r|}
\hline 0.5469 & 0.4531 & $\mathbf{0 . 0 9 4}$ \\
\hline 0.5418 & 0.4582 & $\mathbf{0 . 0 8 4}$ \\
\hline 0.4846 & 0.5154 & $\mathbf{- 0 . 0 3 1}$ \\
\hline 0.1988 & 0.8012 & $\mathbf{- 0 . 6 0 2}$ \\
\hline 0.3017 & 0.6983 & $\mathbf{- 0 . 3 9 7}$ \\
\hline 0.2807 & 0.7193 & $\mathbf{- 0 . 4 3 9}$ \\
\hline 0.7051 & 0.2949 & $\mathbf{0 . 4 1 0}$ \\
\hline
\end{tabular}

\begin{tabular}{|r|r|r|}
\hline 0.6812 & 0.3188 & $\mathbf{0 . 3 6 2}$ \\
\hline 0.3611 & 0.6389 & $\mathbf{- 0 . 2 7 8}$ \\
\hline 0.5196 & 0.4804 & $\mathbf{0 . 0 3 9}$ \\
\hline 0.6836 & 0.3164 & $\mathbf{0 . 3 6 7}$ \\
\hline 0.8996 & 0.1004 & $\mathbf{0 . 7 9 9}$ \\
\hline 0.9090 & 0.0910 & $\mathbf{0 . 8 1 8}$ \\
\hline 0.4366 & 0.5634 & $\mathbf{- 0 . 1 2 7}$ \\
\hline
\end{tabular}

In the case of an distribution-adjusted occurrence of smaller than 1 , we have replaced the respective values with an occurrence of 1 .

** Terms such as 'Sovjet Union', 'European Union', or 'Norwich Union' have been excluded from the results

*** $\mathrm{dO}=\left(\mathrm{O}_{\mathrm{UK}} / \mathrm{O}_{\mathrm{UK}+\mathrm{US}}\right)-\left(\mathrm{O}_{\mathrm{US}} / \mathrm{OUK}+\mathrm{US}\right)$ 
The findings presented in table 4 suggest some preliminary themes emerging from the data analysis.

- Within the coverage of the stakeholders represented in business ethics there are strong similarities between the US and UK groups in terms of government, unions, consumers, and shareholders. The US sample is more likely to consider employees/workers as stakeholders than the UK group.

- The topics covered in business ethics with the UK demonstrate a strong bias towards 'social responsibility', 'environmental', and 'human rights'. This possibly points towards a broader scope of business ethics in the UK whereas there is a more limited scope in the US.

- When comparing the broader topics as well as financial management it can be seen that in the US samples overall adjusted coverage is higher on crime, fraud and reputation than any of the other topics within the US sample (such as tobacco, environmental, sustainable). Whereas in the UK sample the highest adjusted coverage in rank order is crime, environmental, oil, weapons, corruption, reputation and fraud. This again supports the assertion that business ethics in the UK considers a broader range of topics, associated with sustainability and financial management, than in the US.

- Within the instruments used as part of business ethics the main difference relates to the terms 'law' and 'regulation' which are mainly discussed in US context. This is not merely related to Enron - instead, we can see a very high weighting factor pointing towards an equal distribution over time. In contrast, in the UK the term count is a lot lower and occurrence of the term 'law' seems to have been triggered by the high-profile corporate scandals. This is reflected by a weighting factor of only 0.8 .

- There is little use of the terms accountability and transparency in the US, these are mostly used in the UK though overall coverage is also relatively low.

- The more litigious environment is the US is reflected by the higher occurrence of 'laws' though both groups demonstrate high levels of coverage associated with guidelines and standards. This may demonstrate the use of voluntary codes of practice within business ethics and this is reflected more strongly within the UK group, an environment that has typically relied upon market mechanisms to control business conduct, especially when considering broader aspects of environmental management. Whereas, the narrow focus on financial mis-management in the US has been more formally regulated by specific acts of legislation.

- The terms that returned results of less than 10 occurrences included HIV, Sarbanes-Oxley, child labo(u)r, working hours, bribery, (minimum) wage. The absence of these terms also indicates limited scope of business ethics coverage.

\section{Conclusions}

This paper has presented a number of important findings that reflect the contextualisation of business ethics over and time and in different regions. Business ethics as a concept has a base level of coverage within society that has not significantly increased over the last 18 years. This coverage tends to reflect coverage of financial management topics though some regions (such as the UK) may be broadening this to include topics associated with sustainability. There are clear increases in the level of coverage of sustainability topics and it may be that business ethics is being subsumed into this theme and now is known by a different nomenclature. Those events that are seen to be defining moments in business ethics, such as Enron, have an immediate impact, and perhaps policy implications, but do not make a discernable impact on the overall trends in business ethics coverage. Broader policy events such as the Earth Summits are apparently impacting societal coverage and may be demonstrating some form of punctuated equilibrium.

There are clear regional differences in the level of business ethics penetration into society as reflected by media coverage and the US/UK sample suggests that business ethics also covers very different topics 
regionally. Again this has major implications for businesses that operate in different parts of the world. Future research should compare the content of ethical codes of conduct of these types of firms and the content of business ethics articles in the regional newspapers to see if there are synergies between them. Companies could use the techniques identified here to identify the regional priorities that they should address when considering local/regional outreach activities.

A number of studies have examined the content of business codes within the world's major corporations (Carasco and Singh, 2003; Kaptein, 2004; Bthoux et al., 2007). Research suggests that over $50 \%$ of the world's major corporations have a business ethics code, with the majority including aspects associated with environmental issues (Kaptein 2004; Carasco and Singh, 2003) examines the detailed content of 50 of top corporations and found $69 \%$ had some mention of environmental issues, but only 41 discussed civic and community affairs. The business codes for Soco, Wal-Mart and SSAB presented earlier all demonstrate a broad perspective on business ethics that incorporates environmental and social issues more akin to the ideas of sustainability. In contrast, the contextual analysis of the media coverage of business ethics presented here demonstrates differences between the US and UK sample, with media in the US focussing more on aspects of corporate corruption, bribery, or fraud compared to the broader UK perspective. This suggests some form of disconnect between what the media considers as the territory of business ethics and the interpretation by organisations within their codes of practices. This suggests that future research should explore this disconnect in more detail.

Future studies could also consider refining the data collection techniques. In the second part of the analysis presented in this paper, a simplified weighting factor based on the standard distribution of each term was used. Furthermore, inflected or derived forms of each key term were identified manually, and their counts aggregated. A more complex approach could be provided by information extraction (IR) tools, which may be used to perform the ranking of the individual news items on the basis of a given term (Mitkov, 2003). The scores assigned by the tool to the documents could then be used instead of the term counts as an indication of how extensively the corresponding topic has been covered by the newspapers. IR tools such as the Lemur toolkit (Ogilvie and Callan, 2002) also take into account inflected and derived terms with no effort on the part of the user, thus improving the recall of relevant documents. The application of any of these tools could also facilitate the analysis of a considerably larger sample size than used in this analysis, and could also process a considerably larger number of key terms.

It is also important to note that this paper covers the period up to mid 2008, prior to the increased coverage of the global economic crisis and the accountability of the banking sector. Therefore future studies should examine the impact that the financial crisis has had on the context and coverage of business ethics in the media and public domain.

It is clear from this paper that business ethics is a concept that has a durability in society demonstrating sustained levels of coverage over the last 18 years. However it is also clear that the boundaries of what is meant by business ethics are evolving alongside the societal context in which it is framed. As focus deepens on, and societal awareness increases of, the concepts enshrined in sustainability we need to consider how this may lead to a new framing of business ethics.

\section{References}

Banerjee, S. B., lyer, E. S. and Kashyap, R. K. (2003), "Corporate environmentalism: Antecedents and influence of industry type", Journal of Marketing, Vol. 67 No. 2, pp. 106-122.

Bijsmans, P. and Altides, C. (2007) "Bridging the Gap" between EU Politics and Citizens? The European Commission, National Media and EU Affairs in the Public Sphere", Journal of European Integration, Vol. 29 No. 3, pp. $323-340$. 
Brossard, D., Shanahan, J. and McComas, K. (2004), "Are Issue-Cycles Culturally Constructed? A Comparison of French and American Coverage of Global Climate Change", Mass

Communication and Society, Vol. 7 No. 3, pp. 359 - 377.

Bthoux, I., Didry, C. and Mias, A. (2007), "What Codes of Conduct Tell Us: corporate social responsibility and the nature of the multinational corporation", Corporate Governance : An International Review, Vol. 15 No. 1, pp. 77-90.

Carasco, E.F. and Singh, J.B. ( 2003), "The content and focus of the codes of ethics of the world's largest transnational corporations", Business and Society Review, Vol. 108 No. 1, pp. 71-94.

Carson, R., Darling, L. and Darling, L. (1962), Silent spring, Houghton Mifflin; Riverside Press, Boston; Cambridge, Mass.

Corbett, J.B. (2006), Communicating nature how we create and understand environmental messages, Island Press, Washington, DC.

De George, R.T. (1987), "The status of business ethics: past and future", Journal of Business Ethics, Vol. 6, pp. 201-211.

DesJardins, J.R. (2007), Business, Ethics and the Environment, Pearson Education, New Jersey. Downs, A (1972), "Up and Down with Ecology", The Public Interest, No. 28 Summer, pp. 38-50

Ethics Resource Center (2008), "Business ethics timeline", available at http://www.ethics.org/resources/business-ethics-timeline.asp\#d196os (accessed 6.9.08).

Fayyad, U., Piatetsky-Shapiro, G. and Smyth, P. (1996) "From data mining to knowledge discovery: An Overview" in U. Fayyad, G. Piatetsky-Shapiro, Smyth, P. and Uthurusamy R. (Eds.), Advances in Knowledge Discovery and Data Mining, MIT Press, Cambridge, Mass pp. 1-36.

Feldman, R. and Dagan, I. (1995), "Knowledge discovery in textual databases (KDT)", Paper presented at the First International Conference on Knowledge Discovery and Data Mining (KDD-95), Montreal, Canada.

Feldman, R. and Sanger, J. (2007), The Text Mining Handbook, Cambridge University Press, Cambridge, MA.

Fortune (2008), "Global 500 Our annual ranking of the world's largest corporations", available at http://money.cnn.com/magazines/fortune/global500/2008/snapshots/2255.html (accessed 9.9.08)

Gibb, L.M. (1998), Love Canal the story continues, New Society Publishers, Gabriola Island, BC

Hearst, M. A. (1997), "Text data mining: Issues, techniques, and the relationship to information access", Presentation notes for UW/MS workshop on data mining, July 1997.

Hearst, M. A. (1999), "Untangling text data mining", Paper presented at the 37th Annual Meeting of the Association for Computational Linguistics.

Kaptein, M. 2004, "Business Codes of Multinational Firms: What Do They Say?", Journal of Business Ethics, Vol. 50 No. 1, pp. 13-31.

Knouse, S.B., Hill, V.D., and Hamilton III, J.B. (2007), "Curves in the high road a historical analysis of the development of American business codes of ethics", Journal of Management History, Vol. 13 No. 1, pp. 94-107.

Lent, B., Agrawal, R. and Srikant, R. (1997), "Discovering Trends in Text Databases", Paper presented at the 3 rd International Conference on Knowledge Discovery (KDD), 1997.

Lewis, T. L. (2000), "Media Representations of "Sustainable Development: Sustaining the Status Quo?" Science Communication, Vol. 21 No. 3, pp. 244-273.

Manning, C. D. and Schütze, H. (2002), Foundations of Statistical Natural Language Processing, MIT Press, Cambridge, MA.

Mitkov, R. (2003), (Ed), The Oxford Handbook of Computational Linguistics, Oxford University Press, Oxford.

Montes y Gómez, M., Gelbukh, A., and López- López, A. (2001), "Mining the news: trends, associations, and deviations", Computación y Sistemas, Vol 5 No. 1, July-September 
Norris, P. (2001), Digital Divide: Civic Engagement, Information Poverty and the Internet Worldwide, Cambridge University Press, Cambridge.

Ogbonna, E and Harris, LC (2001), "The founder's legacy: hangover of inheritance?" British Journal of Management, Vol. 12 No. 1, pp. 13-31.

Ogilvie, P. and Callan, J. (2002), Experiments using the lemur toolkit, Proceedings of the 2001 Text Retrieval Conference (TREC 2001), pp.103-108.

Piasecki, B (1994) Corporate Strategy: the Avalanche of Change since Bhopal, Wiley, New York

Preuss, L (2008) "Are we talking about the same thing? Comparing business ethics, corporate citizenship, corporate (social responsibility and sustainability", Working paper presented at Seabus Network Conference, 19-22 June 2008 Berlin

Romanelli, E and Tushman, ML (1994), 'Organisational transformation as punctuated equilibrium: an empirical test', Academy of Management Journal, Vol. 37 No. 5, pp. 1141-61

Rossouw, D (2002), Business Ethics in Africa, Oxford University Press, Cape Town, South Africa.

Soco (2008), "Guidelines for the Code of Business Conduct and Ethic", available at http://www.socointernational.co.uk/?id=guidelines_code, (accessed 7.9.08).

SSAB (2008), "SSAB Code of Business Ethics", available at http://www.ssab.com/upload/Verksamhet/Dokument/Policys/SSAB\%20Code\%200f\%20Busines s\%20Ethics\%20-\%20final\%2oupdated\%20HR\%20070816.pdf (accessed 6.9.08).

Tan, A. H. (1999), "Text mining: The state of the art and the challenges", Paper presented at the PacificAsia Conference on Knowledge Discovery and Data Mining PAKDD'g9 workshop on Knowledge Discovery from Advanced Databases.

Valenti, J. M. (2003), "Commentary: Media Coverage of the World Summit on Sustainable Development", Science Communication, Vol. 24 No. 3 pp.380-386.

Vogel, D. (1993), "Representing Diffuse Interests in Environmental Policy Making" in Weaver, R.K. and Rockman, B.A. (Eds.), Do institutions matter? Government capabilities in the United States and abroad, Brookings Institution, Washington, Washington DC.

Wal-Mart (2008), "Ethical sourcing", available at http://walmartstores.com/AboutUs/279.aspx (accessed 7.9.08).

\section{Endnote}

$1 \operatorname{Textanz}^{1}$ (http://www.cro-code.com/textanz.jsp, Ver. 2.4.1.0) 